Dückers, M.L.A. A multilayered psychosocial resilience framework and its implications for community-focused crisis management Journal of Contingencies and Crisis Management: 2017, 25(3), 182-187

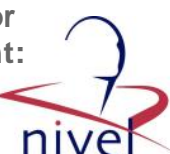

\begin{tabular}{|l|l|}
$\begin{array}{l}\text { Postprint } \\
\text { Version }\end{array}$ & 1.0 \\
\hline Journal website & http://onlinelibrary.wiley.com/doi/10.1111/1468-5973.12183/full \\
\hline Pubmed link & $10.1111 / 1468-5973.12183$ \\
\hline DOI &
\end{tabular}

This is a NIVEL certified Post Print, more info at http://www.nivel.eu

\title{
A multilayered psychosocial resilience framework and its implications for community-focused crisis management
}

\author{
MICHEL L.A. DÜCKERS \\ Impact - National Knowledge and Advice Centre for Psychosocial Care Concerning Critical \\ Incidents, Partner in Arq Psychotrauma Expert Group, Diemen, The Netherlands \\ NIVEL - Netherlands Institute of Health Services Research, Utrecht, The Netherlands
}

\begin{abstract}
The focus of this contribution is on the psychosocial well-being, health, and functioning of communities in the context of major crises. A multilayered psychosocial resilience framework is described, conceptualizing and connecting capacities at individual, community, and society levels. Effective crisis management is strengthening and utilizing these capacities. The community as a resilient, functioning social system depends, almost by definition, on collaboration among government, business, and civil society. Yet while resilience and crisis management form a logical combination, resilience for its part is depoliticized and naturalizing, whereas crisis management can be controversial and politically intense, which in practice means crisis management might negatively affect the development of more resilient communities.
\end{abstract}

\section{INTRODUCTION}

Resilience is a popularized and formal concept in different branches of scientific research, including the social sciences (Alexander, 2013; Comfort, Boin, \& Demchak, 2010; Duit, 2016; Olsson, Jerneck, Thoren, Persson, \& O'Byrne, 2015). Different authors have focused on the devastating effects of disasters and major crises on individuals, communities, and societies in terms of loss of lives, safety, health, livelihood, communality, functioning, and productivity (Bonanno, Brewin, Kaniasty, \& La Greca, 2010; Bourque, Siegel, Kano, \& Wood, 2007; Dückers, Rooze, \& Alexander, 2014; Erikson, 1976; Perry, 2007). According to Boin and 't Hart (2005, p. 43), crises occur "when core values or life-sustaining systems of a community come under threat" with "widely shared values such as safety and security, welfare and health, integrity and fairness" becoming unstable or even meaningless. The constellation of concepts revolving around adaptation, coping, recovery, and "bouncing back," which is an intrinsic feature of resilience, explains 
Dückers, M.L.A. A multilayered psychosocial resilience framework and its implications for community-focused crisis management Journal of Contingencies and Crisis Management: 2017, 25(3), 182-187

the tendency to incorporate the resilience concept in disaster and crisis management literature.

This contribution is written from a psychosocial perspective, focusing on the wellbeing, health, and functioning of communities confronted by a major crisis. Its relevance and the need to consider both individual and community impacts have been described by Kaniasty and Norris: "Natural disasters, technological catastrophes, and acts of mass terrorism are more than individual-level events; they are community-level events that bring harm, pain, and loss to large numbers of people simultaneously. They are often brutal in their severity and broad in their scope. Many of them involve immediate trauma arising from exposure to death and injury (horror), extreme physical force (terror), and life-threatening situations. They destroy and disturb (...) [and] result in similar psychological consequences, such as symptoms of post-traumatic stress disorder, depression, anxiety, and physical ailments (...). Yet there are potentially important differences among these events in their effects on social and community life." (Kaniasty \& Norris, 2004, p. 200). Understanding possible effects is one thing; addressing them adequately in relation to psychosocial resilience is another. Diversity in crisis effects at different levels, and the variation in coping and adaptive capacities, particularly for serious hazards, demands a comprehensive, cross-sector, multidisciplinary approach. What would such an approach involve? Hereafter psychosocial resilience is conceptualized as a multilayered construct, followed by a discussion on how the theoretical framework can be applied to stimulate the creation of more resilient communities.

\section{PSYCHOSOCIAL RESILIENCE: A CONCEPT WITH MULTIPLE LAYERS}

Norris and colleagues defined resilience as "a process linking a set of adaptive capacities to a positive trajectory of functioning and adaptation after a disturbance" (Norris, Stevens, Pfefferbaum, Wyche, \& Pfefferbaum, 2008, p. 130). This process can take place at least on three levels (individual, community, and society), each with distinctive sets of adaptive capacities that are likely interconnected.

\subsection{Individual level}

Resilience has been used by psychologists to describe an individual's reactions to potentially traumatic events. Bonanno described how "large numbers of people manage to endure the temporary upheaval of loss or potentially traumatic events remarkably well, with no apparent disruption in their ability to function at work or in close relationships, and seem to move on to new challenges with apparent ease" (Bonanno, 2004, p. 20). He emphasizes that resilience differs from recovery: "a trajectory in which normal functioning temporarily gives way to threshold or subthreshold psychopathology (e.g., symptoms of depression or (...) PT SD), usually for a period of at least several months, and then gradually returns to pre-event levels (...). By contrast, resilience reflects the ability to maintain a stable equilibrium" (p. 20). According to Bonanno, most individuals exposed to violent or life-threatening events "show the type of healthy functioning suggestive of the resilience trajectory" (p. 22). A number of them will fully recover within 1 or 2 years or more rapidly, and a minority (approx. 10\%-20\%) will suffer from chronic or delayed psychological problems (Bonanno, 2004).

Different risk factors (or protective when reversed) have been verified, among others: being a woman, lower social economic status, absence of social support, exposure to adversity (being confronted with death, trauma, and loss), and pre- 
Dückers, M.L.A. A multilayered psychosocial resilience framework and its implications for community-focused crisis management Journal of Contingencies and Crisis Management: 2017, 25(3), 182-187

existing mental health problems (Brewin, Andrews, \& Valentine, 2000; Ozer, Best, Lipsey, \& Weiss, 2003). Apart from social support, the capacity to shape and modify one's behaviour to meet the shifting challenges that arise in different situations (optimal adjustment) is ascribed to personality traits such as hardiness, egoresiliency, and adaptive flexibility (Bonanno et al., 2010). According to Ahmed (2007), resilience is promoted by internal characteristics (e.g., optimism, trust, selfefficacy, secure attachments, interpersonal abilities) and external factors (safety, religious affiliation, strong role models, and emotional sustenance).

\subsection{Community level}

The community resilience concept centres on the neighbourhoods and cities in which people live. Community resilience has been referred to as "the ability of human communities to withstand external shocks or perturbations to their infrastructure, such as environmental variability or social, economic or political upheaval, and to recover from such perturbations" (Adger, 2000). Community resilience involves the connection among the physical in terms of infrastructures such as roads, bridges, and utilities; technical systems such as phones and Internet; and humans through individual-, group- and organization-level interactions (Busch \& Givens, 2013; Kendra \& Wachtendorf, 2003; Powley, 2003). When it comes to organizations and businesses, it should be noted that organizations are communities or sources of community themselves, and employers of citizens, with their resilience being part of the equation (Doerfel, Lai, \& Chewning, 2010; Kendra \& Wachtendorf, 2003). From a psychosocial perspective, the human aspect is a core theme, not to be seen apart from the physical aspect as infrastructure and technical systems are enablers of resilience (or barriers when hampered). Psychosocially, community resilience has been described as "community-level adaptation" in relation to "population wellness"- "a high prevalence of wellness in the community, defined as high and non-disparate levels of mental and behavioural health, role functioning, and quality of life in constituent populations" (Norris et al., 2008; p. 133).

Norris and colleagues conceptualized community resilience as a set of networked adaptive capacities:

economic development (...): fairness in the distribution of risk and vulnerability to hazards; the level and diversity of economic resources; equity of resource distribution;

social capital (...): received (enacted) social support; perceived (expected) social support; social embeddedness (informal ties); organizational linkages/cooperation; citizen participation, leadership and roles (formal ties); sense of community; attachment to place; information and communication (...): narratives, responsible media, skills and infrastructure; trusted sources of information;

community competence (...): community action, critical reflection and problem solving skills; flexibility and creativity; collective efficacy/empowerment; political partnerships (p. 136).

\subsection{Society level}

Communities are part of a broader society. The capacity of societies to return to a stable order depends heavily on the presence of socio-economic, political, and institutional conditions, together with operational structures and resources. The more precisely these conditions are met, the more resilient a society is likely to be in the 
Dückers, M.L.A. A multilayered psychosocial resilience framework and its implications for community-focused crisis management Journal of Contingencies and Crisis Management: 2017, 25(3), 182-187

face of disaster. Nevertheless, it is usually simply a matter of time before weaknesses in capacity expose themselves. If this happens, it has a negative impact on ability to manage and recover from disasters (Dückers et al., 2014).

This national capacity is captured in the World Vulnerability Index: a periodically updated index comprising over 20 cultural and socio-economic country data sets. Items in the index are clustered in three groups: susceptibility to negative impacts, lack of coping capacities, and lack of adaptive capacities (Welle \& Birkmann, 2015a,b). Less vulnerable countries are characterized by good governance, low levels of corruption, access to health care and education, higher public and private health expenditure, gross national product per individual, income equality, and life expectancy, among other indicators. These countries have better developed systems to provide professional psychosocial services in the wake of calamities (Dückers, Frerks, \& Birkmann, 2015; Dückers, Witteveen, Bisson, \& Olff, 2015). Yet and in contrast to patterns found at individual level, populations living in less vulnerable countries run a higher risk of developing mental disorders (PTSD and mood disorders in particular), especially when they are more exposed to potentially traumatic events (Dückers, Alisic, \& Brewin, 2016; Dückers \& Brewin, 2016). This "vulnerability paradox" may be linked to a lower availability of social support (an individual-level protective factor) in less vulnerable countries (inhabited by more individualistic cultures; see Dückers, Frerks, \& Birkmann, 2015; Dückers, Witteveen, Bisson, \& Olff, 2015).

\subsection{Cross-level interactions}

Community resilience links the capacities at the society-level to individual-level capacities and other factors within the framework. At all three levels, several adaptive capacities help make it possible to regain equilibrium, in a mechanical sense but also notably in terms of attachment to place and space. "Communal activities may be thwarted for all residents of affected areas simply because physical environments, settings, and places instrumental for maintaining a sense of continuity and interpersonal contacts are damaged or destroyed. Residents of places ruined by disasters often report decreased participation in social activities with relatives, friends, neighbours, and community organizations (...). Routine activities such as visiting, shopping, recreation, and attending religious services are necessarily reduced and, with them, the daily opportunities to convey and preserve the sense of support and feeling of being reliably connected to people and the community. Also, loss of attachments to places is psychologically hurtful because physical structures with their familiar symbolic and social dimensions are foundations of self- and collective-identities." (Kaniasty \& Norris, 2004, p. 205; also see Erikson, 1976). Again, organizations and businesses can also be portrayed as communities or sources of community. Their continuation or return matters as an economical resource. Moreover, identities are attached to faith, church, community as well as work (c.f. Mael \& Ashforth, 1992). This illustrates how, although different, many pertinent factors at different levels are likely connected, where lower-level capacities depend, to a certain extent, on capacities at higher levels. Resilient individuals contribute to resilient communities that drive the response and recovery capacity of societies, and the other way around. Capacities at the different levels are linked to the psychosocial health, well-being, and functioning of populations in a crisis context. 
Dückers, M.L.A. A multilayered psychosocial resilience framework and its implications for community-focused crisis management Journal of Contingencies and Crisis Management: 2017, 25(3), 182-187

\section{DEVELOPMENT OF MORE RESILIENT COMMUNITIES}

This framework serves here as a starting point for exploring approaches to achieve and maintain resilient communities in the wake of adversity which, if it is not a crisis management task, is an endeavour that influences effective crisis management. Crisis management involves deliberate efforts to deal with the consequences of crises "before, during and after they have occurred" (Shrivastava, Mitroff, Miller, \& Miglani, 1988; p. 287; also see Boin, 't Hart, Stern, \& Sundelius, 2016). Three issues have practical implications for strategies to develop more resilient communities: time stages, coordination and alignment, and political dynamics.

\subsection{Time stages}

The time stages before, during, and after a crisis are relevant for coping and adaptive capacities with respect to the different levels of the framework. From a preventive or planning perspective, the ideal (although unrealistic) strategy would be to prevent major natural or human-made events or threats from occurring. A more feasible path is to invest proactively in detecting and resolving weak spots or deficiencies in capacities at different levels, including critical infrastructure, and strengthen them beforehand. People can be trained and methods tested. However, it is uncertain whether specific exogenous capacities - particularly those at individual and society level (personality traits, socio-economic country characteristics) — can be influenced significantly or, even if they can, whether it can be done soon enough.

Furthermore, during and after the crisis, crisis management can help to limit the impact on individual capacities, for example, by bringing people into safety, providing shelter and basic first aid, family reunification, and psychosocial services. A logical approach, given the relevance of individual-level features (such as safety, religious affiliation, strong role models, and emotional sustenance), is to make use of capacities at community level and, in the case of a large-scale event, benefit from available capacity for response and recovery at national level or beyond.

\subsection{Coordination and alignment}

When a crisis occurs, it is tackled by networks of organisations, which cut across disciplinary, jurisdictional, and public-private sector boundaries (Hilliard, 2000; Kapucu, 2008). This applies as well to investments in the various capacities at society and community levels. The resilience of a society is to a considerable extent determined by the breadth and depth of interprofessional or interorganizational relationships within its crisis management systems. "Just having high-performing components within that system is not good enough; it is the linkages between components that make or break systemic resilience" (Boin \& 't Hart, 2011, p. 366). However, managing community resilience is complex and involves coordination across public and private sectors (Doerfel, 2016). Within the community, many actors play a role in the creation and maintenance of capacities, including capacities and risk factors at individual level and local manifestations of society-level capacities (e.g., quality and integrity of the governing system, health and education services accessible to the population, operational infrastructure). From various sectoral perspectives, governmental and nongovernmental organizations, professionals and volunteers, corporations, community actors such as schools, religious organizations, sport clubs, and local or national media, and charity organizations must join forces to strengthen and utilize economic development, social capital, information and communication, and community competence. Alexander (2010) provides an account 
Dückers, M.L.A. A multilayered psychosocial resilience framework and its implications for community-focused crisis management Journal of Contingencies and Crisis Management: 2017, 25(3), 182-187

of how restoration of community capacities was omitted in the recovery programme for survivors after the first years following the earthquake in L'Aquila, Italy in 2010: " $[\mathrm{N}]$ othing was invested in transportation and services, leaving sites that had populations of up to 2,500 people devoid of shops, community centres, coffee bars, bus services, clinics, schools, and doctors' surgeries. Moreover, little attention was paid to the problem of conserving social cohesion in the assignment of transitional housing units. This has led to high levels of isolation, depression and post-traumatic stress among the assignees" (Alexander, 2010, p. 9). Such is why disaster recovery should involve coordinated cooperation, carefully designed and well-resourced community programmes, and active target group involvement through all phases from planning to evaluation. Boin and 't Hart follow a similar line of reasoning when they emphasize how "enhancing community resilience and planning the interface between government, business, and community sectors in crisis management should be part and parcel of the planning process. This presupposes levels of cross-sectoral involvement and dialogue that are neither self-generating nor self-sustaining. It requires community participation in crisis planning, particularly within high-salience 'at risk' communities" (Boin \& 't Hart, 2011, p. 361).

Several examples can be found. After the tsunami in South-East Asia (2004), international organizations and the mass media underestimated crucial local capacities and neglected the skills of local actors and context-specific requirements. While the international community collected vast amounts of money, problematic coordination and ignorance of local coordination mechanisms led to an unbalanced, inequitable flow of funding, lack of investment in local capacities and failure to respond adequately to local needs (Telford, Cosgrave, \& Houghton, 2006). The aftermath of the 2010 earthquake in Haiti, one of the most vulnerable countries according to the World Risk Report, was hindered by knowledge of the operational environment, sustainable support, and effective investments in capacity. A stronger connection with local actors, embedded in regular coordination mechanisms, would have resulted in more efficient recovery process (IASC, 2010; Welle \& Birkmann, 2015a).

What capacity-building and crisis management have in common is a need for coordinated planning and the delivery of measures and interventions. The level of success depends heavily on the alignment among professionals, disciplines, organizations, policy domains, and governmental layers. Smooth interactions depend on social trust, sense of urgency, awareness of interdependencies, shared interests, compatible ideologies and habits, roles, personal idiosyncrasies, even coincidence.

\subsection{Political dynamics}

Olsson and colleagues concluded that core concepts and theories in social science, such as agency, conflict, knowledge, and power, are absent from resilience theory, making resilience "a powerful depoliticizing or naturalizing scientific concept and metaphor when used by political actors" (Olsson et al., 2015, p. 9). In this respect, resilience and crisis management could not be more different. Crisis management should not be viewed just in terms of coping capacities, but "it should be considered a deeply controversial and intensely political activity" (Boin \& "t Hart, 2005; p. 49). This has to do with accountability, and even the survival of responsible authorities confronted with increased criticism and public pressure. The political dimension goes further than that. In fact, the cornerstones of traditional political models are, to a greater or lesser extent, blended in the social system of crisis management and 
Dückers, M.L.A. A multilayered psychosocial resilience framework and its implications for community-focused crisis management Journal of Contingencies and Crisis Management: 2017, 25(3), 182-187

community resilience. Olsson et al. (2015) exemplify how Parsons' notion of a social system resembles resilience theory. Parsons stated that a social system (i) must adapt to its physical and social environment as well as adapt the environment to its needs (adaptation; condition: develop industries and markets, science and technology), (ii) must define and achieve its primary goals (goal attainment; condition: societies need to develop political institutions), (iii) must coordinate and regulate interrelationships of its components and strive towards a cohesive whole (integration; condition: develop civil society and religion), (iv) must furnish, maintain and renew itself and stimulate its individuals to perform their roles according to social and cultural expectations (latency; condition: develop families and schools) (see Parsons, 1951, p. 241-242). Government, business, and civil society (including family and the private sphere) equip the resilient social system to perform its four functions. As a coordination model, business, government and civil society each have pitfalls the opposing models can compensate. In addition, boosting adaptation, freedom, and entrepreneurship can result in inequality, lack of solidarity with the less fortunate, lack of cohesion, and other negative effects that can be regulated or otherwise counterbalanced by government, and civil society. The government route, for instance, is a means to pursue equality and public interests, yet emergency powers, geared in a postdisaster setting of securitization, need to have proper democratic underpinnings (Alexander, 2010; Cooper \& Block, 2006). Civil society has the potential to nurture cohesion and solidarity, but also benefits from what the other models can provide in the areas of science and technology (business), and the safety valve they provide which maintains legitimate laws and serves the interests of ingroups and out-groups (including - more vulnerable - marginalized groups and ethnic minorities) (government).

\section{CONCLUSION}

This contribution focused on communities as resilient social systems confronted with crises, equipped with a certain capacity to anticipate the negative impact on psychosocial health, well-being, and functioning. Community capacities to deal with adversity are closely connected, however, to capacities at individual and society level. Effective crisis management involves strengthening and utilizing these capacities as well. A practical challenge is to equally distribute scarce resources between and within communities and to plan and coordinate activities by professionals and volunteers who operate autonomously or in organizations and multilayered interorganizational networks, while benefiting to the maximum from contemporary science and technology.

The community as a resilient functioning social system depends on collaboration among government, business, and civil society. Yet while resilience and crisis management form a logical combination, resilience for its part is depoliticized and naturalizing, whereas crisis management is potentially controversial and politically intense. When discussion takes place in a resilience vocabulary, sensitivities can be avoided for the time being. Still, in practice, this does not prevent possible tensions, even conflict of interests, while strengthening and utilizing community capacities before, during, and after a major crisis. 
Dückers, M.L.A. A multilayered psychosocial resilience framework and its implications for community-focused crisis management Journal of Contingencies and Crisis Management: 2017, 25(3), 182-187

\section{REFERENCES}

Adger, W. N. (2000). Social and ecological resilience: Are they related? Progress in Human Geography, 24(3), 347-364.

Ahmed, A. S. (2007). Post-traumatic stress disorder, resilience and vulnerability. Advances in Psychiatric Treatment, 13(5), 369-375.

Alexander, D. (2010). The L'Aquila earthquake of 6 April 2009 and Italian Government policy on disaster response. Journal of Natural Resources Policy Research, 2(4), 325-342.

Alexander, D. (2013). Resilience and disaster risk reduction: An etymological journey. Natural Hazards and Earth System Sciences, 13(11), 2707-2716.

Boin, A., \& 't Hart, P. (2005). The crisis approach. In H. Rodríguez, E. L. Quarantelli \& R. R. Dynes (Eds.), Handbook of disaster research (pp. 42-54). New York, NY: Springer.

Boin, A., \& 't Hart, P. (2011). Organising for effective emergency management: Lessons from research. Australian Journal of Public Administration, 69(4), 357-371.

Boin, A., t Hart, P., Stern, E., \& Sundelius, B. (2016). The politics of crisis management: Public leadership under pressure, 2nd ed. New York, NY: Cambridge University Press.

Bonanno, G. A. (2004). Loss, trauma, and human resilience. Have we underestimated the human capacity to thrive after extremely aversive events? American Psychologist, 59(1), 20-28.

Bonanno, G. A., Brewin, C. R., Kaniasty, K., \& La Greca, A. M. (2010). Weighing the costs of disaster: Consequences, risks, and resilience in individuals, families, and communities. Psychological Science in the Public Interest, 11(1), 1-49.

Bourque, L. B., Siegel, J. M., Kano, M., \& Wood, M. M. (2007). Morbidity and mortality associated with disasters. In H. Rodríguez, E. L. Quarantelli \& R. R. Dynes (Eds.), Handbook of disaster research (pp. 97-112). New York, NY: Springer.

Brewin, C. R., Andrews, B., \& Valentine, J. D. (2000). Meta-analysis of risk factors for posttraumatic stress disorder in trauma-exposed adults. Journal of Consulting and Clinical Psychology, 68(5), 748-766.

Busch, N. E., \& Givens, A. D. (2013). Achieving resilience in disaster management: The role of public-private partnerships. Journal of Strategic Security, 6(2), 1-19.

Comfort, L. C., Boin, A. \& Demchak, C. (Eds.) (2010). Designing resilience: Preparing for extreme events. Pittsburgh, PA: Pittsburgh University Press.

Cooper, C., \& Block, R. (2006). Disaster: Hurricane Katrina and the failure of homeland security. New York, NY: Times Books.

Doerfel, M. L. (2016). Networked forms of organizing, disaster-related disruptions, and public health. In T. R. Harrison, \& E. A. Williams (Eds.), Organizations, communication, and health (pp. 365-383). New York, NY: Routledge.

Doerfel, M. L., Lai, G.-H., \& Chewning, L. V. (2010). The evolutionary role of interorganizational communication: Modeling social capital in disaster contexts. Human Communication Research, 26(2), 125-162.

Dückers, M. L. A., Alisic, E., \& Brewin, C. R. (2016). A vulnerability paradox in the crossnational prevalence of PTSD. The British Journal of Psychiatry, 209(4), 300-305.

Dückers, M. L. A., \& Brewin, C. R. (2016). A paradox in individual versus national mental health vulnerability. Journal of Traumatic Stress, 29(6), 572-576.

Dückers, M., Frerks, G., \& Birkmann, J. (2015). Exploring the plexus of context and consequences: An empirical test of a theory of disaster vulnerability. International Journal of Disaster Risk Reduction, 3, 85-95.

Dückers, M., Rooze, M., \& Alexander, D. (2014). Towards resilient organization of recovery and care after disaster. In J. J. L. M. Bierens (Ed.), Drowning: Prevention, rescue, treatment (2nd ed., pp. 1033-1038). Berlin Heidelberg: Springer-Verlag.

Dückers, M. L. A., Witteveen, A. B., Bisson, J. I., \& Olff, M. (2015). The association between disaster vulnerability and post-disaster psychosocial service delivery across Europe. Administration and Policy in Mental Health and Mental Health Services Research, DOI: 10.1007/s10488-015-0671-8.

Duit, A. (2016). Resilience thinking: Lessons for public administration. Public Administration, 94(2), 364-380.

Erikson, K. T. (1976). Everything in its path: Destruction of community in the Buffalo Creek Flood. New York, NY: Simon \& Schuster. 
Dückers, M.L.A. A multilayered psychosocial resilience framework and its implications for community-focused crisis management Journal of Contingencies and Crisis Management: 2017, 25(3), 182-187

Hilliard, M. (2000). Public crisis management: How and why organizations work together to solve society's most threatening problems. Lincoln: Writer's Club Press.

IASC (2010) Response to the humanitarian crisis in Haiti following the 12 January earthquake. Inter-Agency Standing Committee.

Kaniasty, K., \& Norris, F. H. (2004). Social support in the aftermath of disasters, catastrophes, and acts of terrorism: Altruistic, overwhelmed, uncertain, antagonistic, and patriotic communities. In R. Ursano, A. Norwood, \& C. Fullerton (Eds.), Bioterrorism: Psychological and public health interventions (pp. 200-229). Cambridge, UK: Cambridge University Press.

Kapucu, N. (2008). Collaborative emergency management: better community organizing, better public preparedness and response. Disasters, 32(2), 239-262.

Kendra, J., \& Wachtendorf, T. (2003). Elements of resilience after the World Trade Center disaster: Reconstituting New York City's Emergency Operations Centre. Disasters, 27(1), 37-53.

Mael, F. A., \& Ashforth, B. E. (1992). Alumni and their alma mater: A partial test of the reformulated model of organizational identification. Journal of Organizational Behavior, 13(2), 103-123.

Norris, F. H., Stevens, S. P., Pfefferbaum, B., Wyche, K. F., \& Pfefferbaum, R. L. (2008). Community resilience as a metaphor, theory, set of capacities, and strategy for disaster readiness. American Journal of Community Psychology, 41(1-2), 127-150.

Olsson, L., Jerneck, A., Thoren, T., Persson, J., \& O'Byrne, D. (2015). Why resilience is unappealing to social science: Theoretical and empirical investigations of the scientific use of resilience. Science Advances, 1(4), e140021.

Ozer, E. J., Best, S. R., Lipsey, T. L., \& Weiss, D. S. (2003). Predictors of posttraumatic stress disorder and symptoms in adults: A meta-analysis. Psychological Bulletin, 129(1), 52-73.

Parsons, T. (1951). Social system. London, UK: Routledge.

Perry, R. W. (2007). What is a disaster? In H. Rodrıguez, E. L. Quarantelli, \& R. R. Dynes (Eds.), Handbook of disaster research (pp. 441-455). New York, NY: Springer.

Powley, E. H. (2003). Reclaiming resilience and safety: Resilience activation in the critical period of crisis. Human Relations, 62(9), 1289-1326.

Shrivastava, P., Mitroff, I. I., Miller, D., \& Miglani, A. (1988). Understanding industrial crises. Journal of Management Studies, 25(4), 285-304.

Telford, J., Cosgrave, J., \& Houghton, R. (2006). Joint evaluation of the international response to the Indian Ocean tsunami: Synthesis report. London, UK: Tsunami Evaluation Coalition, ALNAP.

Welle, T., \& Birkmann, J. (2015a). The world risk index 2015. In J. Jeschonnek, P. Mucke, K. Radtke, \& J. Walter (Eds.), World risk report 2015 (pp. 40-49). Berlin: Alliance Development Works.

Welle, T., \& Birkmann, J. (2015b). The world risk index: An approach to assess risk and vulnerability on a global scale. Journal of Extreme Events, 2(1), 1550003. 